NASA/TM-2003-212496

\title{
Optimal Area Profiles for Ideal Single Nozzle Air-Breathing Pulse Detonation Engines
}

Daniel E. Paxson

Glenn Research Center, Cleveland, Ohio 
Since its founding, NASA has been dedicated to the advancement of aeronautics and space science. The NASA Scientific and Technical Information (STI) Program Office plays a key part in helping NASA maintain this important role.

The NASA STI Program Office is operated by Langley Research Center, the Lead Center for NASA's scientific and technical information. The NASA STI Program Office provides access to the NASA STI Database, the largest collection of aeronautical and space science STI in the world. The Program Office is also NASA's institutional mechanism for disseminating the results of its research and development activities. These results are published by NASA in the NASA STI Report Series, which includes the following report types:

- $\quad$ TECHNICAL PUBLICATION. Reports of completed research or a major significant phase of research that present the results of NASA programs and include extensive data or theoretical analysis. Includes compilations of significant scientific and technical data and information deemed to be of continuing reference value. NASA's counterpart of peerreviewed formal professional papers but has less stringent limitations on manuscript length and extent of graphic presentations.

- TECHNICAL MEMORANDUM. Scientific and technical findings that are preliminary or of specialized interest, e.g., quick release reports, working papers, and bibliographies that contain minimal annotation. Does not contain extensive analysis.

- CONTRACTOR REPORT. Scientific and technical findings by NASA-sponsored contractors and grantees.
- CONFERENCE PUBLICATION. Collected papers from scientific and technical conferences, symposia, seminars, or other meetings sponsored or cosponsored by NASA.

- SPECIAL PUBLICATION. Scientific, technical, or historical information from NASA programs, projects, and missions, often concerned with subjects having substantial public interest.

- TECHNICAL TRANSLATION. Englishlanguage translations of foreign scientific and technical material pertinent to NASA's mission.

Specialized services that complement the STI Program Office's diverse offerings include creating custom thesauri, building customized databases, organizing and publishing research results ... even providing videos.

For more information about the NASA STI Program Office, see the following:

- Access the NASA STI Program Home Page at http://www.sti.nasa.gov

- E-mail your question via the Internet to help@sti.nasa.gov

- Fax your question to the NASA Access Help Desk at 301-621-0134

- Telephone the NASA Access Help Desk at 301-621-0390

- Write to:

NASA Access Help Desk

NASA Center for AeroSpace Information 7121 Standard Drive

Hanover, MD 21076 
NASA/TM-2003-212496

\section{Optimal Area Profiles for Ideal Single Nozzle Air-Breathing Pulse Detonation Engines}

Daniel E. Paxson

Glenn Research Center, Cleveland, Ohio

Prepared for the

39th Joint Propulsion Conference and Exhibit cosponsored by AIAA, ASME, SAE, and ASEE Huntsville, Alabama, July 20-23, 2003

National Aeronautics and

Space Administration

Glenn Research Center 
This report is a formal draft or working paper, intended to solicit comments and ideas from a technical peer group.

This report contains preliminary findings, subject to revision as analysis proceeds.

The Propulsion and Power Program at NASA Glenn Research Center sponsored this work.

NASA Center for Aerospace Information 7121 Standard Drive

Hanover, MD 21076
National Technical Information Service 5285 Port Royal Road Springfield, VA 22100 
AIAA-2003-4512

\title{
OPTIMAL AREA PROFILES FOR IDEAL SINGLE NOZZLE AIR-BREATHING PULSE DETONATION ENGINES
}

\author{
Daniel E. Paxson ${ }^{\dagger}$ \\ National Aeronautics and Space Administration \\ Glenn Research Center \\ Cleveland, Ohio 44135
}

\begin{abstract}
The effects of cross-sectional area variation on idealized Pulse Detonation Engine performance are examined numerically. A quasi-one-dimensional, reacting, numerical code is used as the kernel of an algorithm that iteratively determines the correct sequencing of inlet air, inlet fuel, detonation initiation, and cycle time to achieve a limit cycle with specified fuel fraction, and volumetric purge fraction. The algorithm is exercised on a tube with a cross sectional area profile containing two degrees of freedom: overall exit-to-inlet area ratio, and the distance along the tube at which continuous transition from inlet to exit area begins. These two parameters are varied over three flight conditions (defined by inlet total temperature, inlet total pressure and ambient static pressure) and the performance is compared to a straight tube. It is shown that compared to straight tubes, increases of 20 to 35 percent in specific impulse and specific thrust are obtained with tubes of relatively modest area change. The iterative algorithm is described, and its limitations are noted and discussed. Optimized results are presented showing performance measurements, wave diagrams, and area profiles. Suggestions for future investigation are also discussed.
\end{abstract}

\section{INTRODUCTION}

The performance of a Pulse Detonation Engine (PDE) can be strongly affected by the shape of the tube wall, of which it is essentially comprised. This fact is intuitively clear if the gasdynamic nature of the device is considered, and has been pointed out in numerical and experimental investigations. ${ }^{1,2,3}$ Most of these investigations have focused on the aft end of the PDE and have therefore been called nozzle studies; however,

\footnotetext{
'Senior Member AIAA, Phone: 216-433-8334, Fax: 216-433-8643, E-mail:Daniel.E.Paxson@grc.nasa.gov

This material is declared a work of the U. S. Government and is not subject to copyright protection in the United States.
}

there is no particular reason for limiting them to this region. In fact, the phrase "nozzle," usually associated with gas expansion processes, may be somewhat misleading in the PDE since it is not yet clear whether the changes in performance arise due to the expansion or the compression and/or detonation processes in area varying regions.

Despite the efforts to date, there have been no firm conclusions drawn as to whether the effects of nozzle (or any other region) shaping are, from a gasdynamic viewpoint, beneficial or detrimental. This is partly due to the fact that contradictory results have been obtained, depending on whether limit-cycle or one-shot operation is considered. ${ }^{4}$ One-shot operation is that in which the PDE tube, with no inlet (i.e. a solid wall at the inlet end), is filled to some point with a quiescent, detonable mixture, and fired one time. Limit cycle operation is that in which a given tube fires and refills to the same state periodically, and (presumably) indefinitely. Another factor in the inconclusive results of shaping is that many of the previous studies are systematically incomplete. Different, isolated geometries have been considered, but no sweep of the parametric range has been performed.

This paper represents a preliminary effort to fill that void. Using a validated, quasi-one-dimensional, timeaccurate, CFD code ${ }^{5}$ operating within an iterative algorithm, ideal limit cycles may be obtained for any specified tube cross-sectional profile and operating mode. Since the code is relatively rapid, parametric evaluation of geometry and operational mode are practical. The paper will first define the operational modes or parameters. A description of the algorithm for obtaining limit cycles will then be presented, along with a discussion of its limitations. Next, the particular geometrical variations examined will be described, as will the flight conditions (Mach Number, ambient pressure, and ambient temperature) which in this paper set the boundary conditions imposed on the code and 
algorithm. Results will then be presented. These will quantify the performance enhancements, and detail the area distribution parameters used to obtain them, at each of the flight conditions.

An isolated, ideal PDE is considered in this paper, with 'ideal' here implying:

- Instantaneous and lossless valves

- Adiabatic walls

- A single, calorically perfect working gas

- Instantaneous detonation

- Quasi-one-dimensional (Q-1-D), inviscid flow

- One-step chemistry

With this description, the PDE operation is governed by the reactive, Q-1-D Euler equations. These may be solved (integrated) numerically, which is done so here using a robust, well-tested code that has been described in the literature. ${ }^{5}$ The idealizations described do not suppose quasi-steady operation, since such an assumption does not, in the author's opinion allow meaningful assessment of area profiling.

\section{OPERATIONAL MODE PARAMETERS}

The operational mode, or operating point, is controlled by the following parameters:

- Fill Fraction, $\mathrm{F}_{\mathrm{f}} \equiv \frac{\overline{\dot{\mathrm{m}}}_{\text {inlet }}}{\rho_{0 \mathrm{i}} \mathrm{Vf}}$

- Reactant Fraction, $R_{f} \equiv \frac{\overline{\dot{m}}_{\text {reactant }}}{\overline{\dot{m}}_{\text {inlet }}}$

- $\quad$ Flight Conditions, $\mathrm{P}_{0 \mathrm{i}}, \mathrm{T}_{0 \mathrm{i}}, \mathrm{p}_{\mathrm{amb}}$

- Fuel Heating Value

- Reactant equivalence ratio

In Eqs. (1) and (2) $\rho_{0 \mathrm{i}}$ is the inlet stagnation density, $V$ is the tube volume, $f$ is frequency, $\overline{\dot{m}}$ is the timeaveraged mass flow rate, and the subscript reactant refers to the detonable fuel air mixture. The Fill Fraction, $F_{f}$ compares the mass of reactant or air entering the tube each cycle with the mass of air that would occupy the tube at the inlet stagnation conditions. It was suggested in Ref. 5 that this parameter has a fairly modest effect on performance for straight tubes. The impact with area variation is unknown, and it is thus included here. Under static flight conditions, $F_{f}$ is also the fraction of the tube volume that is filled with fresh charge or air each cycle. At higher flight speeds this is not the case.

The Reactant Fraction, $R_{f}$ measures how much of the inlet flow is reactant and how much is pure air. The general effect of this parameter has been demonstrated elsewhere. ${ }^{5,6}$ In terms of stand-alone thrust devices,
Table 1 Flight Conditions

\begin{tabular}{|l|l|l|l|l|}
\hline $\begin{array}{c}\text { Mach \# } \\
\mathrm{M}_{\infty}\end{array}$ & $\begin{array}{c}\mathrm{P}_{0 \mathrm{i}} \\
(\mathrm{psia})\end{array}$ & $\begin{array}{c}\mathrm{T}_{0 \mathrm{i}} \\
(\text { Deg. } \mathrm{R})\end{array}$ & $\begin{array}{c}\mathrm{p}_{\text {amb }} \\
(\mathrm{psia})\end{array}$ & $\begin{array}{l}\mathrm{q}_{0} \\
\gamma \mathrm{R}_{\mathrm{g}} \mathrm{T}_{0 \mathrm{i}}\left(1+\frac{\mathrm{a}}{\mathrm{f}}\right)\end{array}$ \\
\hline 0.0 & 14.7 & 520 & 14.7 & 23.05 \\
\hline 0.5 & 14.6 & 524 & 12.5 & 22.87 \\
\hline 1.0 & 17.9 & 552 & 9.8 & 21.71 \\
\hline
\end{tabular}
${ }^{*} \mathrm{q}_{0} \equiv$ "reat of Reaction, $\mathrm{R}_{\mathrm{g}} \equiv$ (eal Gas Constant

reducing Reactant Fraction increases fuel specific impulse at the expense of specific thrust.

The flight conditions are determined by a specified Mach number, $\mathrm{M}_{\infty}$ and altitude. Assuming a perfect inlet, these in turn determine the inlet total pressure and temperature and exit static pressure. Three conditions are considered in this paper. They are shown in Table 1 , where $P_{0 \mathrm{i}}$ is the inlet total pressure, $\mathrm{T}_{0 \mathrm{i}}$ is the inlet total temperature, and $\mathrm{p}_{\mathrm{amb}}$ is the ambient static pressure (not necessarily the same as the exit plane pressure of the PDE). The total and static conditions of Table 1 are the inlet and exit boundary conditions imposed on the numerical code.

The effects of fuel heating value are relatively selfevident, and they will not be examined in this paper. For reference, the fuel used is Hydrogen, with a heating value assumed to be $51571 \mathrm{BTU} / \mathrm{lb}_{\mathrm{m}}$. The oxidizer is air, thus the corresponding stoichiometric oxidizer-tofuel ratio (denoted $\frac{\mathrm{a}}{\mathrm{f}}$ ) is 34 . Note that the numerical code used in this study is, as mentioned, a single gas code. Thus, one set of gas properties must be used. This was chosen to be those of the $\mathrm{H}_{2} /$ Air mixture with Molecular weight $21 \mathrm{~g} . / \mathrm{mol}$., and a ratio of specific heats $\gamma=1.3$. The value of $\gamma$ used is an average based on pre- and post-detonative temperature.

The effects of reactant equivalence ratio variation also will not be examined herein. The reasons for this are twofold. First, reliable detonations are generally difficult to achieve far from the stoichiometric mixture ratio. Thus, as a practical matter it is likely that PDE's will typically operate near the stoichiometric point. Second, under the assumptions stated above, a change in mixture ratio is equivalent to altering the heating value. For reference, the non-dimensional, stoichiometric, heats of reaction for the given flight conditions examined are shown in the last column of Table 1. 


\section{LIMIT CYCLE ALGORITHM}

The algorithm into which this code is nested may be described as follows. Given a prescribed tube geometry, and specified boundary conditions (flight Mach Number, etc.), a detonation is initiated in a quiescent, fully fueled tube, at the inlet total temperature and pressure. The inlet is initially closed. The detonation proceeds down the tube and at some point the pressure at the inlet end of the tube drops below the inlet total pressure. At this point, denoted $\tau_{\text {open, }}$, the inlet is opened. An arbitrary initial value is chosen for the time at which reactant (stoichiometric air and fuel) should be introduced to the system in order to obtain the target value of Reactant Fraction, $R_{f}^{\text {target }}$. This time will be denoted $\tau_{\mathrm{f}}$. Typical initial values of $\tau_{\mathrm{f}}$ were two times $\tau_{\text {open. }}$. Integration continues with pure air being allowed into the tube prior to $\tau_{\mathrm{f}}$ and reactant after. A running integration of mass entering the tube is monitored. When the specified Fill Fraction has been reached, the inlet closes. At this point, denoted $\tau_{\text {cycle, }}$, the cycle ends. The actual value of $R_{f}$ is computed and compared to the target value. This is used to obtain a new guess for $\tau_{\mathrm{f}}$ using

$$
\tau_{\mathrm{f}}^{\text {new }}=\tau_{\text {open }}+\left(\tau_{\mathrm{f}}^{\text {old }}-\tau_{\text {open }}\right)\left(\frac{\mathrm{R}_{\mathrm{f}}}{\mathrm{R}_{\mathrm{f}}^{\text {target }}}\right)^{\mathrm{n}}
$$

where $n$ is a power that may change with successive iterations. The numerical code is then restarted; however, the initially quiescent gas in the tube is replaced with that at the end of the previous cycle. A detonation is then initiated and the process just described is repeated again. This looping continues until the difference between $\tau_{f}^{\text {new }}$ and $\tau_{f}^{\text {old }}$ is below a set limit. During this iterative process the total mass flowing into and out of the tube is measured over the course of one cycle. The difference between the two will be defined as the cyclic stored mass, $M_{\text {stored }}^{\text {cyclic }}$ If this number is small or zero, the cycle is complete. If not, the iterative procedure described above is continued with the value of $\tau_{f}$ now frozen. As the procedure continues, the total stored mass is also monitored. This is defined as the sum of all $\mathrm{M}_{\text {stored }}^{\text {cyclic }}$ values and will be denoted $\mathrm{M}_{\text {stored }}^{\text {total }}$ When either $\mathrm{M}_{\text {stored }}^{\text {cyclic }}$ or $\mathrm{M}_{\text {stored }}^{\text {total }}$ drops below a specified limit, the cycle is considered completed. This convergence criteria for the total stored mass was added because it was observed that, even with $\tau_{\text {open }}, \tau_{\mathrm{f}}$, and $\tau_{\text {cycle }}$ established, true limit cycle behavior (i.e. the gas state in the tube having an identical distribution to some previous time) sometimes required several cycles. Thus, the convergence criteria allowed for what might be called 'multi-cycle' limit cycles.

The iterative procedure presented above results in the highest frequency operation achievable for a specified set of parameters, to be described below. This, in turn provides the highest possible performance since it maximizes the extent of the thrust producing portion of the cycle as a fraction of the cycle time.

Since this iterative procedure utilizes a CFD (albeit quasi-one-dimensional) code, it is necessarily time intensive. In an effort to minimize this time, only 200 equally spaced numerical cells were utilized to define the computing space. The largest possible time step was also utilized in order to reduce computing time. It is noted that this same grid-spacing (and associated time step) has been used in other numerical studies and in comparison with experimental measurements, with reasonably accuracy. ${ }^{5}$ Furthermore, since this paper is intended to compare the effects of different shapes, it is essentially important only that a consistent grid-spacing was used. For reference however, a brief comparison is presented in Appendix 1 between the present Q-1-D code and the axisymmetric code of Ref. 4.

An example of a converged cycle is shown in Fig. 1. This figure also illustrates the Fill Fraction and Reactant fraction parameters. The figure shows contour plots of non-dimensional pressure, temperature, Mach Number, and local fuel distribution ( $1=$ fueled, $0=$ unfueled air) for one representative limit-cycle with static flight conditions. The cross-sectional area profile used is also shown in the figure and will be described later. The value of $F_{f}$ was 0.4 , and $R_{f}$ was 0.8 . For each contour the vertical dimension represents time. The quantities $\tau_{\text {open }}, \tau_{\mathrm{f}}$, and $\tau_{\text {cycle }}$ are shown on the far right contour. The horizontal dimension is distance along the tube. The black rectangular regions in the lower left of each contour illustrate regions where the inlet is closed. The propagation of the detonation is visible at the bottom of each contour. Comparing the contours labeled Reactant and Temp., it can be seen that not all of the inlet flow is fueled, and that only a portion of the tube is filled with air or detonable mixture.

\section{Limitations}

Several situations arose while exercising the algorithm and code that led to the exclusion of the resulting cycle from consideration in performance comparisons. These are described below. 

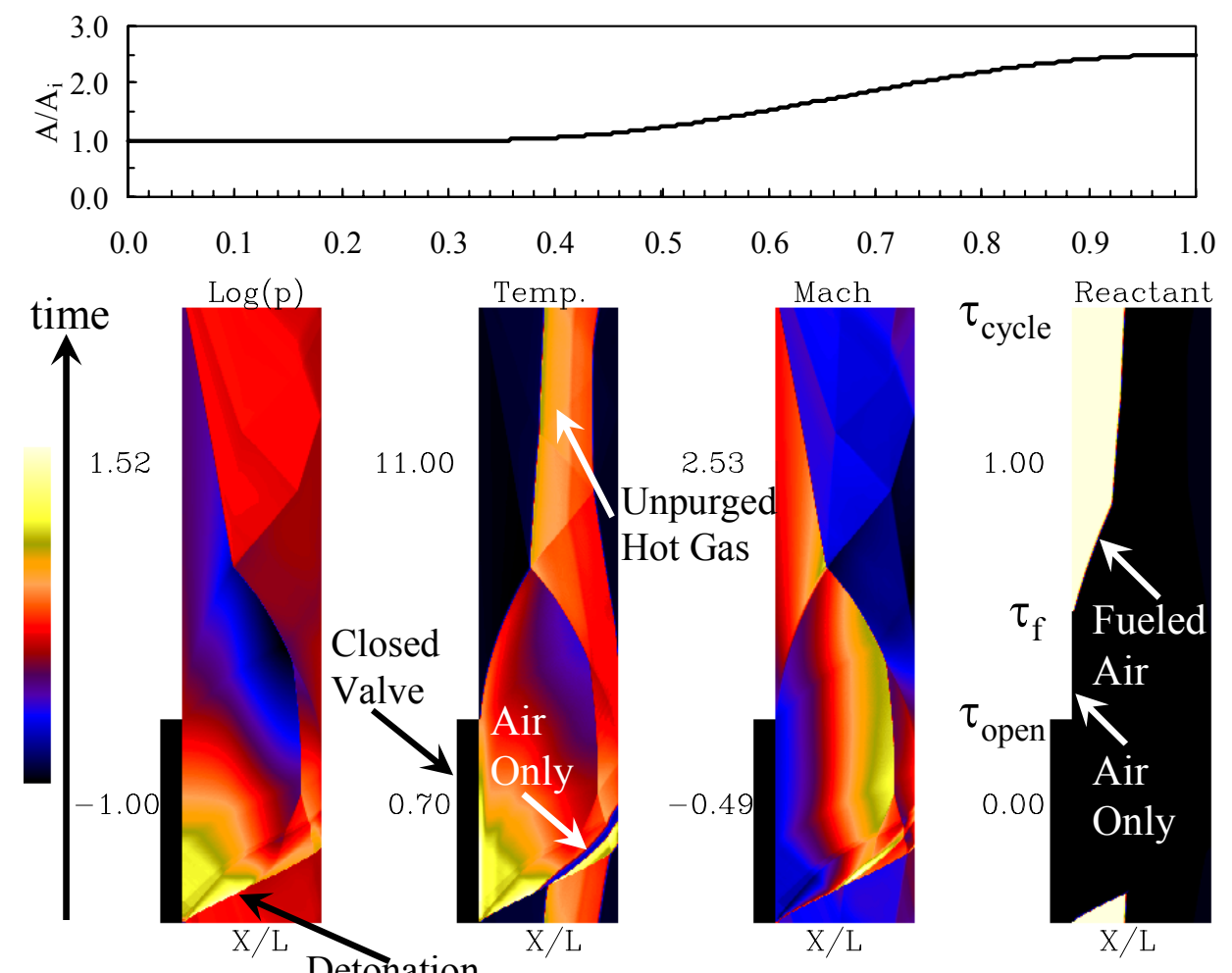

Fig. 1 Contours of non-dimensional Log(pressure), Temperature, Mach number, and detonable mixture fraction for one ideal PDE limit cycle with the cross-section area distribution shown $(\delta / \mathrm{L}=0.33, A R=2.5) . R_{f}=0.80$, and $F_{f}=0.40$, at static flight conditions. The ratio of specific heats, $\gamma=1.3$. The vertical dimension is time. Values beside each contour represent the minimum and maximum in the $x$-t space.

Inlet Flow Reversal

Cycles exhibiting inlet outflow during any part of the refill stage were rejected. Aerodynamic losses associated with inlet flow reversal are not reflected in the performance analysis to be described. Furthermore, outflow in the inlet region of a PDE leads to uncertainties in the fuel distribution. For example, if fueled air were to come out of the inlet, and then flow back in, there is the potential for doubly fueling it. Inlet flow reversals result from shock waves traveling upstream. These shocks can arise from numerous sources, but are often formed by the reflection of the strong exhausting expansion fan reflecting from the constant pressure exit of the PDE tube. Cycles with flow reversal were not observed in straight tubes for any of the flight conditions examined. That is to say, the phenomenon was unique to those tubes with area variations.

\section{Non-Converging Cycles}

Occasional cycles would result in which either $\tau_{\mathrm{f}}$ would not converge to a single value or the stored mass would not reach an acceptably small value compared to the through-flow mass. The causes of these odd cycles are not clear at this time. A limit was set for the number of iterations allowed; however, it does not appear that increasing these limits would alter the outcome. The algorithm tended to converge to some level, and then essentially 'wander' without converging further. More investigation is needed and, in the absence of an explanation for the phenomenon, these 'cycles' were also rejected. Additionally, it was found that some specified $R_{f}, F_{f}$, targets could not be obtained for prescribed area profiles and static boundary conditions. That is to say, the tube would simply never refill to the target value after the detonation event. Clearly, when this situation occurred, no limit cycle could be obtained. The iterative algorithm was therefore halted.

\section{Sonic Inflow}

At higher speed flight conditions, it is possible for sonic or supersonic conditions to exist in the inlet. When this occurs, numerical simulations require additional information at the inflow boundary. In particular, a Mach number must be 
specified in addition to the subsonic requirements of total pressure and temperature. Although the code used in this study is programmed to accept the additional information, it is not clear what value should actually be supplied. The flight Mach number could be used; however, it is generally expected that installed PDE's will have some sort of inlet preceding them. Thus, they are isolated from the external flow, and the external Mach number is not necessarily relevant. With the appropriate Mach number therefore unclear, situations in which sonic or supersonic inflow arose were not considered.

\section{AREA CONTOURS}

The cross-sectional area distributions examined were described by the equation

$$
\begin{aligned}
& \frac{\mathrm{A}}{\mathrm{A}_{\mathrm{i}}}=1 ; 0 \leq \frac{\mathrm{x}}{\mathrm{L}} \leq \frac{\delta}{\mathrm{L}} \\
& \frac{\mathrm{A}}{\mathrm{A}_{\mathrm{i}}}=1+(\mathrm{AR}-1) \sin ^{\mathrm{n}}\left[\frac{\pi}{2}\left(\frac{\mathrm{x}-\delta}{\mathrm{L}-\delta}\right)\right] ; \frac{\delta}{\mathrm{L}}<\frac{\mathrm{x}}{\mathrm{L}} \leq 1
\end{aligned}
$$

where $A_{i}$ is a reference area, $L$ is the length of the PDE, $A R$ is the ratio of exhaust to inlet area, and $n$ is an exponent of arbitrary power. Some examples of this profiling are illustrated in Fig. 2. For all of the calculations performed a value of 2 was used for $n$. Only one value was chosen in an effort to limit the otherwise vast parametric space. This particular value of $n$ yields cross-sectional profiles with continuous slopes (i.e. continuous $\mathrm{dA} / \mathrm{dx}$ ) along the tube and with zero slope at the end of the tube. These features tend to yield better results in quasi-one-dimensional codes; however, they are not required.

\section{PERFORMANCE METRICS}

The measurements of PDE performance used to assess the various parametric variations are fuel specific impulse, and/or specific thrust. These are defined as follows:

$$
\begin{aligned}
& \mathrm{I}_{\mathrm{sp}}=\frac{\overline{\mathrm{T}}}{\overline{\dot{\mathrm{m}}}_{\text {fuel }}}\left(\frac{\mathrm{g}_{\mathrm{c}}}{\mathrm{g}}\right) \\
& \mathrm{T}_{\mathrm{sp}}=\frac{\overline{\mathrm{T}}}{\overline{\dot{\mathrm{m}}}_{\mathrm{i}}}
\end{aligned}
$$

where $\overline{\mathrm{T}}$ is the time-averaged thrust, $g_{c}$ is the Newton constant and $g$ is gravitational acceleration. The timeaveraged thrust is computed using

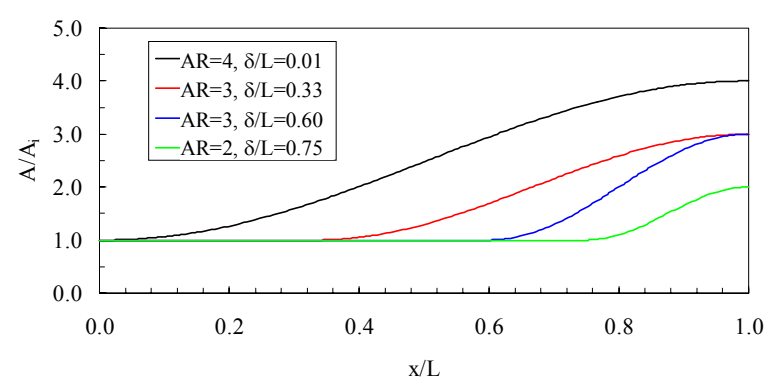

Fig. 2 Various tested cross-sectional area contours illustrating Eqn. 4, with $n=2$.

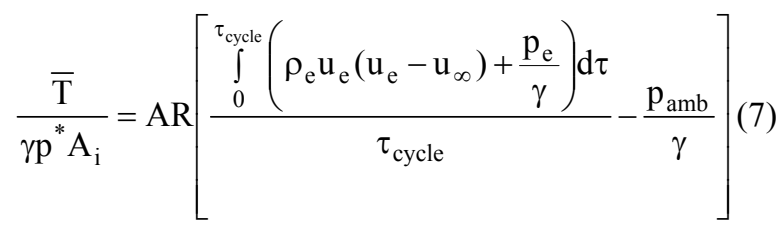

In this equation, the subscript e refers to the exit plane of the $\mathrm{PDE}^{7}$. All quantities on the right hand side of Eq. (6) are non-dimensionalized as described in Ref. 5 . The quantity $p^{*}$ is a reference pressure. For all nondimensional quantities shown in this paper, the reference state is the inlet stagnation state.

The time-averaged inlet mass flow rate, $\overline{\dot{m}}_{i}$ is found using

$$
\frac{\overline{\mathrm{m}}_{\mathrm{i}} \mathrm{a}^{*}}{\gamma \mathrm{p}{ }^{*} \mathrm{~A}_{\mathrm{i}} \mathrm{g}_{\mathrm{c}}}=\mathrm{AR} \frac{\int_{0}^{\tau_{\text {cycle }}}\left(\rho_{\mathrm{e}} \mathrm{u}_{\mathrm{e}}\right) \mathrm{d} \tau}{\tau_{\text {cycle }}}
$$

where $\mathrm{a}^{*}$ is the reference speed of sound. The timeaveraged fuel mass flow rate, $\overline{\dot{m}}_{\text {fuel }}$ is then

$$
\overline{\dot{m}}_{\text {fuel }}=\frac{\mathrm{R}_{\mathrm{f}} \overline{\dot{\mathrm{m}}}_{\mathrm{i}}}{1+\frac{\mathrm{a}}{\mathrm{f}}}
$$

The non-dimensional flight velocity is found via

$$
\mathrm{u}_{\infty}=\frac{\mathrm{M}_{\infty}}{\sqrt{1+\frac{\gamma-1}{2} \mathrm{M}_{\infty}^{2}}} \sqrt{\frac{\mathrm{T}_{\mathrm{i}}}{\mathrm{T}^{*}}}
$$

where $\gamma$ is the ratio of specific heats, and $T^{*}$ is the reference temperature. Specific impulse is often used as the only figure of merit for investigations of PDE performance; however, it should be kept in mind that 


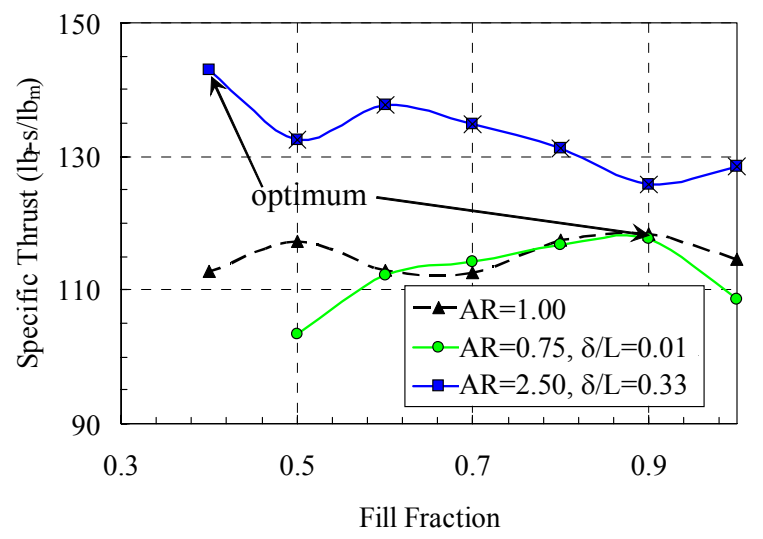

Fig. 3 Specific Thrust as a function of Fill Fraction for several families of $A R$ and $\delta L$, at static flight conditions. The value of $R_{f}$ is 0.80 .

for most propulsion system mission analyses, the optimal solution occurs at a balance between the peaks of specific impulse and specific thrust.

\section{PARAMETRIC OPTIMIZATION}

At each of the selected flight conditions the following procedure is followed. A value for $A R$ is selected and four values of $\delta / L$ are examined: 0.01, 0.33, 0.60, and 0.71 . At each $A R$ and $\delta / L$ combination, four values of $R_{f}$ are sought: $0.97,0.80,0.65$, and 0.50 . At each $R_{f}$ target value, limit cycles are then obtained over a range of $F_{f}$ values.

With $A R, \delta / L$, and $R_{f}$ fixed, there is, a value of $F_{f}$ that yields a maximum specific thrust. This will also be the value yielding peak specific impulse, and thus the best performance given the other three specified parameters (and flight condition). As an example of this, Fig. 3 shows Specific Thrust as a function of $F_{f}$ for several different $A R$, and $\delta / L$ values, with $R_{f}$ fixed at 0.80 . The flight condition is static. The minimum value of $F_{f}$ examined is generally the point where the limit-cycle algorithm will no longer converge. The increment of $F_{f}$ was 0.1. Note that there are often points on these curves that must be excluded from consideration due to one or more of the limitations mentioned earlier. For example, the points on the $A R=2.50$ line that are marked with an ' $\mathrm{X}$ ' were excluded because inlet flow-reversals were observed. This phase of optimization will be denoted as Stage 1.

In the next phase of the optimization process a new value of $\delta / L$ is then chosen and the Stage 1 optimization is again performed ( $A R$, and $R_{f}$ remain fixed). This is

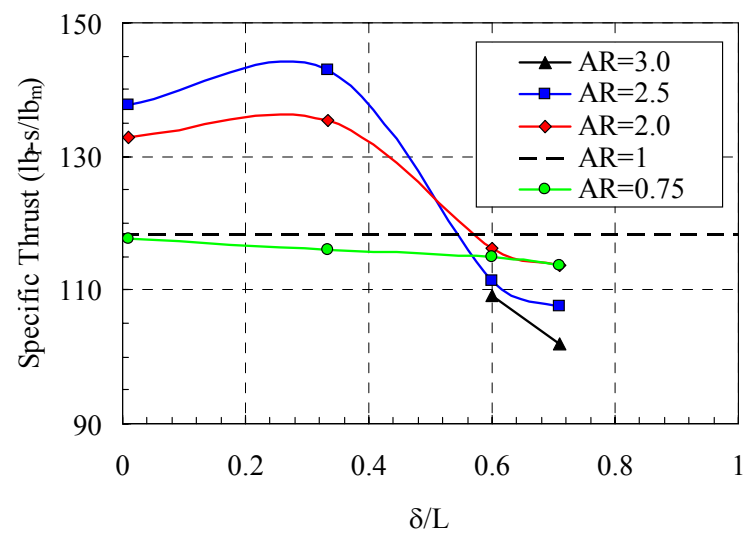

Fig. 4 Specific Thrust as a function of $\delta / L$ for several families of $A R$, with $R_{f}=0.80$, at static flight conditions.

repeated for all four of the selected $\delta / L$ values. Out of these four points, the value of $\delta / L$ yielding the highest specific impulse and specific thrust represents the optimum for a given $A R$, and $R_{f .}$. This will be denoted as Stage 2 optimization. The process is illustrated in Fig. 4 which shows Specific Thrust as a function of $\delta / L$ for several Area Ratios, with $R_{f}$ fixed at 0.80. Again, the flight condition is static. Note that for $A R=3.0$, only two points are plotted. This is because the other two points violated at least one of the limit-cycle limitations for all values of $F_{f}$ during Stage 1. It was assumed that once this occurred, it would occur at all larger values of $A R$. Thus, an upper limit to the values of $A R$ examined was established. It is noted that this assumption has not yet been fully validated.

The value of $A R$ from the Stage 2 optimization yielding the highest Specific Thrust yielded the overall optimal geometry for a given $R_{f}$ and flight condition. The lower limit of AR examined was 0.75 . The results of this optimization are shown in Fig. 5 for the three flight conditions examined. For each flight condition (denoted by Mach Number above the plot), optimal Specific Thrust is shown as a function of Reactant Fraction. The values of $A R, \delta / \mathrm{L}$, and $F_{f}$ at which the values were obtained are also listed. Only one set of these parameters are listed on each plot due to the observation that Stage 1 and Stage 2 optimization produced the same values for all four Reactant Fractions examined. Also shown on the plots are the optimized results for a straight tube, and the corresponding values of $F_{f}$ where they occurred. 

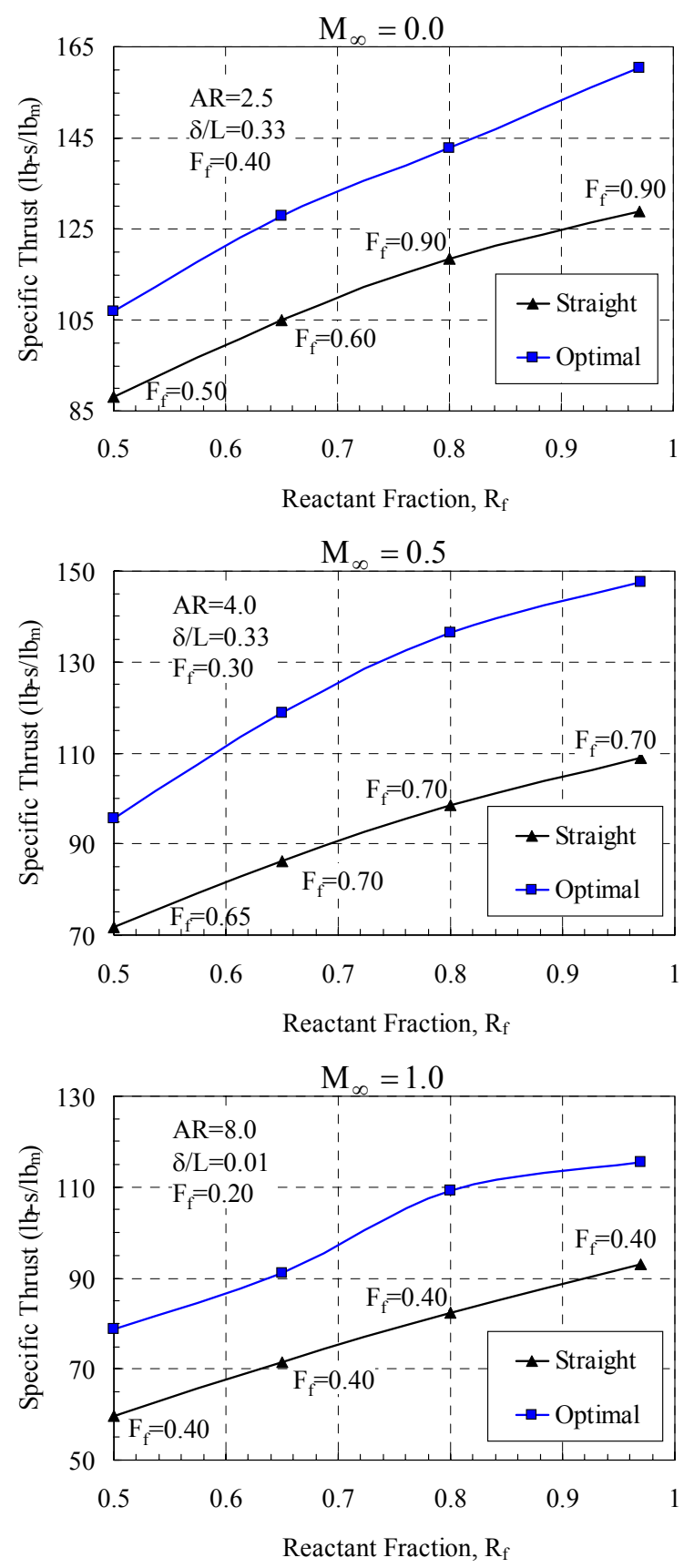

Fig. 5 Optimized Specific Thrust as a function of $\boldsymbol{R}_{f}$, at the flight conditions of Table 1.

For all flight Mach numbers it can be seen that substantial improvements in specific thrust are obtained using optimized area variation. The minimum improvement was $21 \%$, while the maximum was $36 \%$. Recalling from Eqs. (5), (6), and (9) that
Table 2 Non-Dimensional Cycle Times for Area Optimized, and Straight Tubes at Three Flight Conditions

\begin{tabular}{|c|c|c|}
\hline \multirow{2}{*}{$\begin{array}{c}\text { Mach \# } \\
\mathrm{M}_{\infty}\end{array}$} & $\begin{array}{c}|c| \\
\text { Area } \\
\text { Optimized }\end{array}$ & Straight \\
\cline { 2 - 3 } & 1.71 & 3.73 \\
\hline 0.0 & 1.68 & 2.40 \\
\hline 0.5 & 1.99 & 1.52 \\
\hline 1.0 & & \\
\hline
\end{tabular}

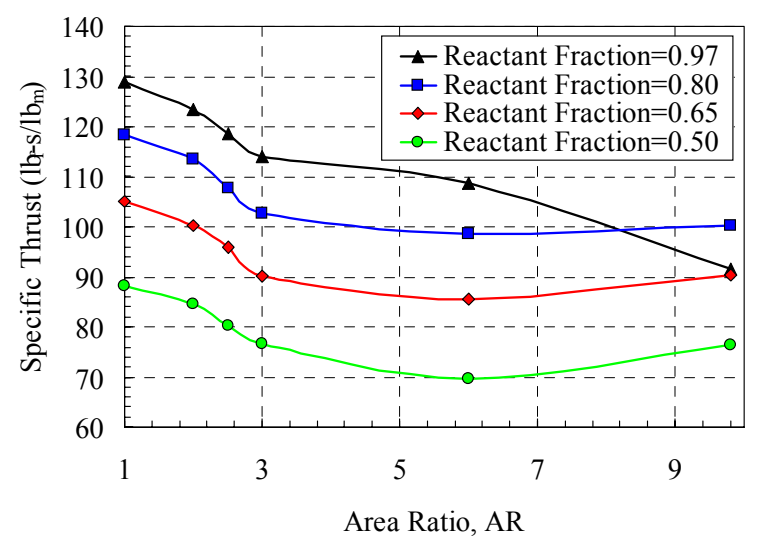

Fig. 6 Specific Thrust, optimized for $F_{f}$, as a function of $A R$, for various families of $R_{f}$, at static flight conditions, with $\delta / L=0.71$

$$
I_{s p}=T_{s p}\left(\frac{1+\frac{a}{f}}{R_{f}}\right)\left(\frac{g_{c}}{g}\right)
$$

it is clear that the same improvements in Specific Impulse are obtained using optimized area variation.

It is interesting to note that for all flight conditions, the value of $\delta / \mathrm{L}$, producing optimal performance was either 0.01 or 0.33 . These are quite different values from the limited cases examined in the literature ${ }^{2,4}$. Such examinations have generally focused on larger $\delta / L$. In this study it was consistently found that the large $\delta / \mathrm{L}=0.71$ case did not lead to performance enhancement. As an example, Fig. 6 shows the Specific Thrust as a function of Area Ratio, with $\delta / \mathrm{L}=0.71$, at static flight conditions. Each point has been optimized only for $F_{f}$. Each curve in the figure represents a different value of $R_{f}$. Similar trends were found at the other flight conditions. 


\section{DISCUSSION}

The mechanism behind the observed performance enhancement is not yet clear. The objective of the current effort was to devise an optimization method to assess whether cross-sectional profiling leads to improved (ideal) performance. Having found that it can, future efforts should focus on why it does. Nevertheless, it is worth briefly examining some of the optimized cycles in detail to see if common features are evident. Figures 7, 8, and 9 show contour plots of optimized cycles, for $R_{f}=0.97$, at the three flight conditions examined. These are similar to Fig. 1 in terms of the information presented and therefore, the same explanation applies. The non-dimensional cycle times, $\tau_{\text {cycle }}=\frac{\mathrm{t}_{\text {cycle }} \mathrm{a}^{*}}{\mathrm{~L}}$ are listed in Table 2 along with the optimized values for the straight tubes.

In each of Figs. 7-9 a strong left-running shock is apparent, evidently originating from the subsonic, constant pressure region of the exit plane. The shock travels upstream and intersects the inlet end at the moment the inlet is closed (and a new detonation is initiated). It appears that the shock acts as a sort of precompression wave, thereby maximizing the pressure in the tube through which the detonation then propagates. This, in turn, yields a higher post detonation pressure on the thrust and side-walls. Although this observation makes intuitive sense, it should be noted that the presence of a coalescing, pre-compression wave is not unique to tubes with area variation. Figure 10 shows the wave diagram for the optimized straight tube with $R_{f}=0.97$, at the $\mathrm{M}_{\infty}=0.5$ flight condition. This is to be compared with Fig. 8 and has been plotted using the same scaling of colors. The same left-running shock is clearly visible. Thus, it seems that the optimization process with respect to $F_{f}$ ensures the presence of a precompression wave which terminates at the closing of the inlet, and that area variation, perhaps, affects its strength.

Although a strong pre-compression wave is a potential mechanism for enhanced performance, it is worthwhile to note that the cycles with area variation also posses substantially lower pressures during portions of a cycle than those without (again compare Figs. 8 and 10). The low pressures occur during the refill process, when the inlet or thrust wall is open; however, with Area Ratios greater than one, they are a source of drag. Thus, the benefit of strong pre-compression may be offset somewhat by additional drag. These competing factors may be responsible for the existence of optimal Area Ratios.
Another interesting feature of the optimized cycles is the large degree of residual (un-purged) hot gas. This is evident in Figs. 7-9. Since the focus of this paper is on idealized flows, issues of heat transfer and material temperature are not considered; however, it should be pointed out that residual hot gas raises the cooling requirements of the system. In general, cooling techniques result in a performance penalty. This must therefore eventually be weighed against the gain observed in the present results.

Associated with the residual hot gas are the very short cycle times required by the optimized cycles. These are listed in Table 2. Typical full-fill cycles have nondimensional cycle times of 4.0 , or more under static flight conditions. This means that for a given length of the PDE tube, the optimized cycles require much higher frequency operation. Given the difficulties in obtaining high frequency operation in state-of-the-art PDE valves, the requirement of even higher frequencies should probably be viewed as a detriment.

Despite these potential shortcomings however, the level of performance enhancement observed from the use of area variation is impressive. It would be interesting and worthwhile to validate the results with a high resolution, multi-dimensional code and/or experimental measurements.

\section{CONCLUSION}

A parametric optimization method has been described, allowing a preliminary performance assessment of cross-sectional area variation in PDE tubes. A two parameter area variation description was chosen and optimized limit-cycles were obtained based on these and two additional parameters (Fill Fraction, and Reactant Fraction) associated with all PDE cycles. For the three flight conditions examined, it was found that 20-35\% improvements in Specific Impulse and Specific Power were possible using smooth, diverging tubes compared with a straight-tube PDE. The gasdynamic mechanism behind the enhancement is not clear; however, further investigation is clearly warranted.

\section{REFERENCES}

1. Kailasanath, K., "A Review of Research on Pulse Detonation Engine Nozzles," AIAA paper 20013932, July, 2001.

2. Cambier, J.-L. and Tegnér, J.K., "Strategies for Pulsed Detonation Engine Performance Optimization," AIAA Journal of Propulsion and Power, Vol. 14, No. 4, 1998, pp. 489-498. 
3. Danioau, E., et al., "Effects of Nozzles of Different Length and Shape on the Propulsion Performance of Pulsed Detonation Engines," High Speed Deflagration and Detonation, ed. G. Roy, S. Frolov, D. Netzer, A. Borisov, Elex-kn Publishers, Moscow, 2001, pp. 251-262.

4. Yungster, S., "Analysis of Nozzle Effects on Pulse Detonation Engine Performance," AIAA paper 2002-1316, January, 2003.
5. Paxson, D.E., “A Performance Map for Ideal AirBreathing Pulse Detonation Engines," AIAA paper 2001-3465, July, 2001.

6. Schauer, F., Stutrud, J., Bradley, R., "Detonation Initiation Studies and Performance Results for Pulsed Detonation Engine Applications" AIAA Paper 2001-1129, January, 2001.

7. Foa, J.V., Elements of Flight Propulsion, John Wiley and Sons, 1960. 

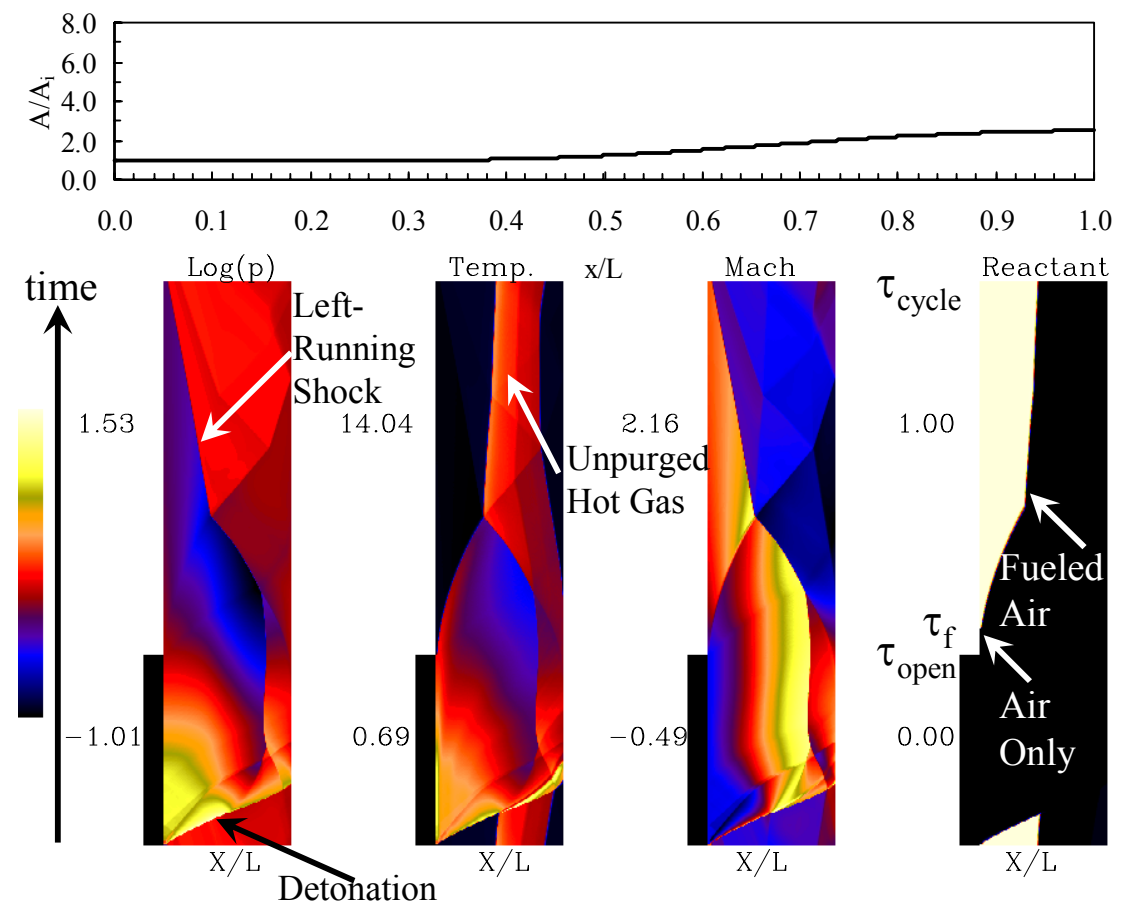

Fig. 7 Contours of non-dimensional $\log$ (pressure), Temperature, Mach number, and detonable mixture fraction for the optimized, ideal PDE limit cycle with the cross-section area distribution shown $(\delta / \mathrm{L}=0.33, A R=2.5)$, $R_{f}=0.97$, and $F_{f}=0.40$, at static flight condition.
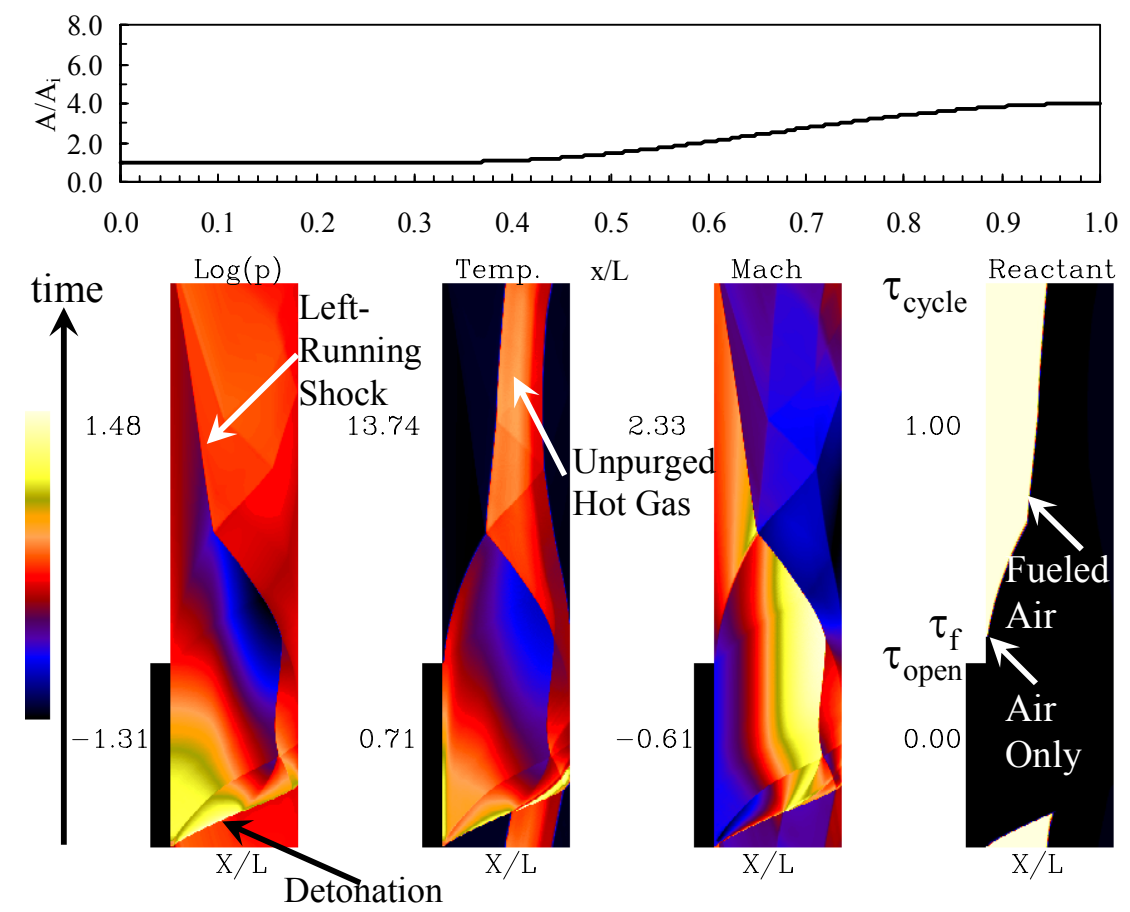

Fig. 8 Contours of non-dimensional $\log$ (pressure), Temperature, Mach number, and detonable mixture fraction for the optimized, ideal PDE limit cycle with the cross-section area distribution shown $(\delta / L=0.33, A R=4.0)$, $R_{f}=0.97$, and $F_{f}=0.30$, at $M_{\infty}=0.5$ flight condition. 

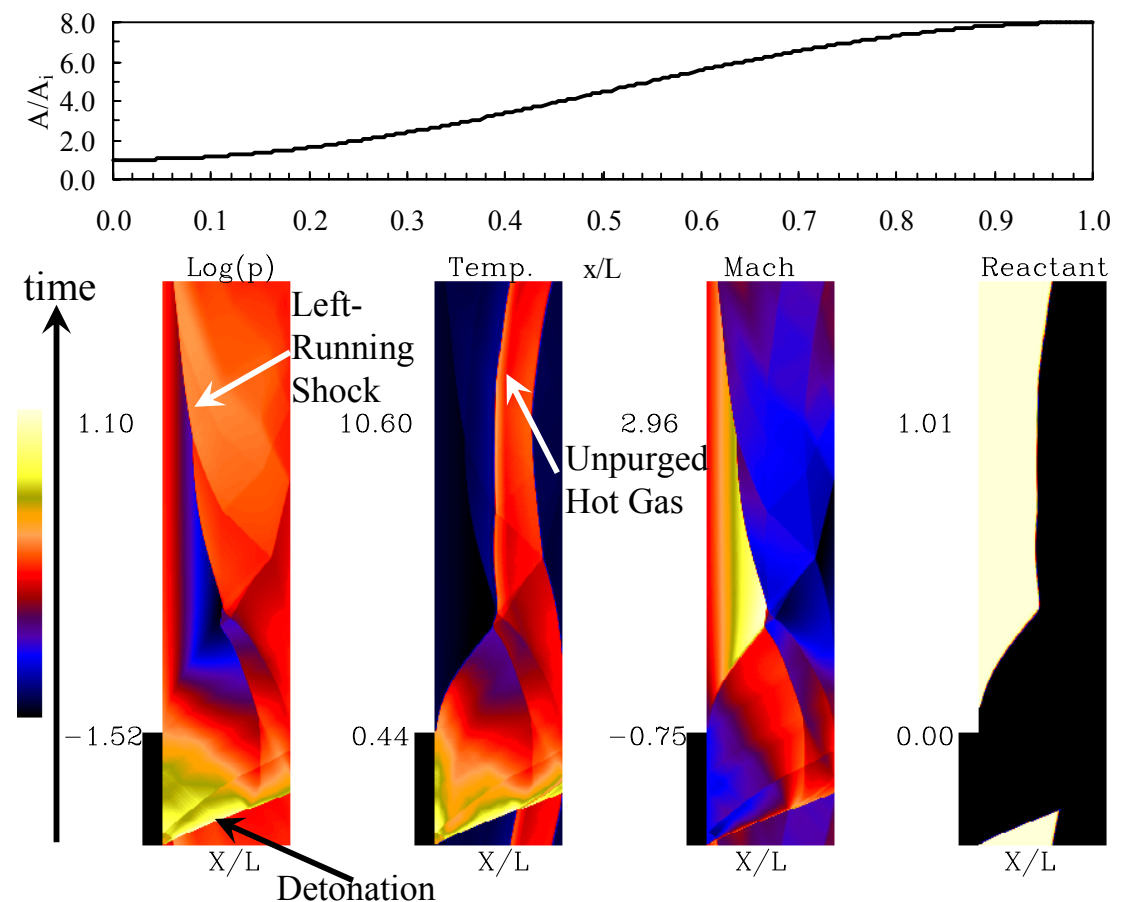

Fig. 9 Contours of non-dimensional Log(pressure), Temperature, Mach number, and detonable mixture fraction for the optimized, ideal PDE limit cycle with the cross-section area distribution shown $(\delta / L=0.01, A R=8.0)$, $R_{f}=0.97$, and $F_{f}=0.20$, at $M_{\infty}=1.0$ flight condition.
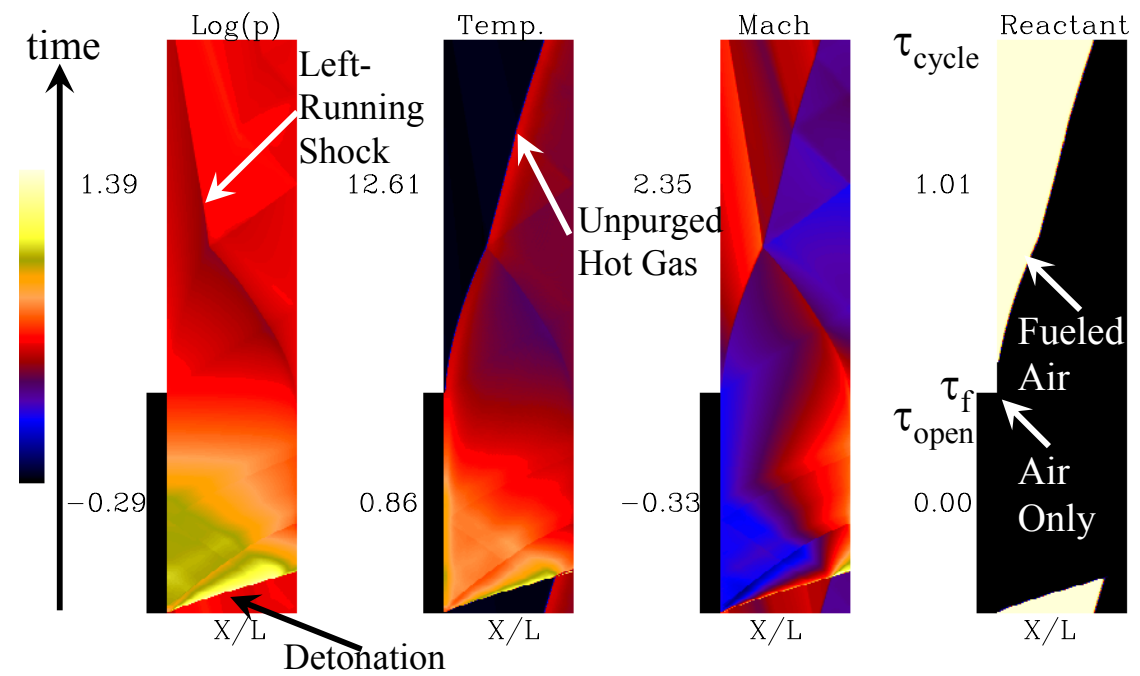

Fig. 10 Contours of non-dimensional $\log$ (pressure), Temperature, Mach number, and detonable mixture fraction for the optimized, ideal PDE limit cycle with no cross-sectional area variation, $R_{f}=0.97$, and $F_{f}=0.70$, at $M_{\infty}=0.5$ flight condition. 



\section{APPENDIX 1}

The present Q-1-D code, and associated grid spacing was compared to the axisymmetric code described in Ref. 4 for a series of so-called one-shot computations. In these simulations, the PDE tubes are partially fueled with a quiescent, stoichiometric mixture of Hydrogen and Air, at ambient conditions. The remainder of the tube is filled with pure air. The detonation is then initiated and the simulations proceed for a prescribed amount of time. The inlet end of the PDE tubes remains closed during the entire simulation.

Two cross-sectional profiles were considered, one straight and one flared, as shown in Fig. A1. In both case the tubes were filled to $71 \%$ of their length with detonable mixture. A third case was also considered, which was a straight, but shortened tube. This tube was completely filled with detonable mixture. It is denoted in the figures as the Baseline.

Figure A2 shows the computed Specific Impulse as a function of time for the three cases, using the two codes. The agreement between the baseline computations is excellent. For the partially fuelled cases there is an approximately $18 \%$ difference in the results. Note however, that this difference is the same with and without area variation. Thus, it arises not from the Q-1$\mathrm{D}$ approach, but from the fact that the present code allows only one set of gas properties. This results in the post-detonation shock propagating through a much less dense gas than that in Ref. 4. Recall that Q-1-D code assumes that all gas has the properties of stoichiometric Hydrogen/Air, whereas the Ref. 4 code does not. This results in errors with the present code, however they are similar regardless of the tube geometry. Thus the use of the present code for comparisons of geometry is well justified. Note, for example, that in the partially fueled cases, the ratio of Specific Impulse with area variation, to that without, is the same for both codes.

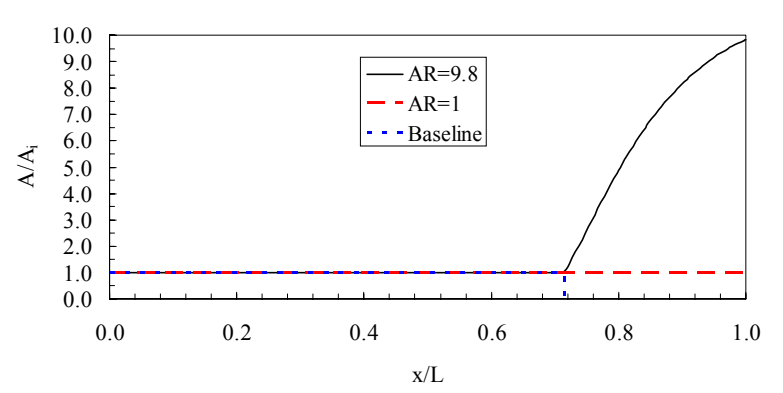

Fig. A1 Cross-sectional area profiles used in comparison study.

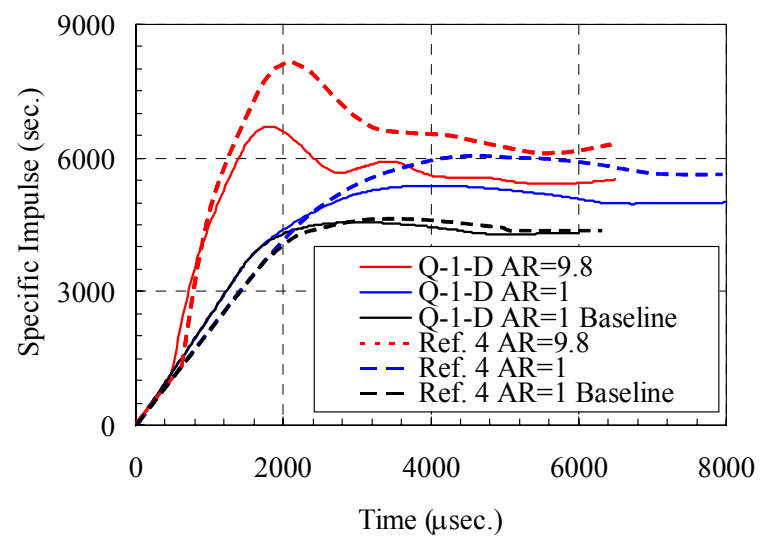

Fig. A2 Computed Specific Impulse for the three one-shot cases. Solid lines are from the present code, dashed line are from Ref. 4 . 
Public reporting burden for this collection of information is estimated to average 1 hour per response, including the time for reviewing instructions, searching existing data sources, gathering and maintaining the data needed, and completing and reviewing the collection of information. Send comments regarding this burden estimate or any other aspect of this collection of information, including suggestions for reducing this burden, to Washington Headquarters Services, Directorate for Information Operations and Reports, 1215 Jefferson Davis Highway, Suite 1204, Arlington, VA 22202-4302, and to the Office of Management and Budget, Paperwork Reduction Project (0704-0188), Washington, DC 20503.

\begin{tabular}{|l|l|l}
\hline 1. AGENCY USE ONLY (Leave blank) & $\begin{array}{c}\text { 2. REPORT DATE } \\
\text { July } 2003\end{array}$ & $\begin{array}{r}\text { 3. REPORT TYPE AND DATES COVERED } \\
\text { Technical Memorandum }\end{array}$ \\
\hline
\end{tabular}

\section{TITLE AND SUBTITLE}

5. FUNDING NUMBERS

Optimal Area Profiles for Ideal Single Nozzle Air-Breathing Pulse

Detonation Engines

6. AUTHOR(S)

Daniel E. Paxson

WBS-22-708-48-09

7. PERFORMING ORGANIZATION NAME(S) AND ADDRESS(ES)

National Aeronautics and Space Administration

John H. Glenn Research Center at Lewis Field

Cleveland, Ohio 44135-3191

8. PERFORMING ORGANIZATION

REPORT NUMBER

E-14057

9. SPONSORING/MONITORING AGENCY NAME(S) AND ADDRESS(ES)

National Aeronautics and Space Administration

Washington, DC 20546-0001

10. SPONSORING/MONITORING

AGENCY REPORT NUMBER

NASA TM-2003-212496

AIAA-2003-4512

\section{SUPPLEMENTARY NOTES}

Prepared for the 39th Joint Propulsion Conference and Exhibit cosponsored by AIAA, ASME, SAE, and ASEE, Huntsville, Alabama, July 20-23, 2003. Responsible person, Daniel E. Paxson, organization code 5530, $216-433-8334$.

12a. DISTRIBUTION/AVAILABILITY STATEMENT

12b. DISTRIBUTION CODE

Unclassified - Unlimited

Subject Category: 07

Distribution: Nonstandard

Available electronically at http://gltrs.grc.nasa.gov

This publication is available from the NASA Center for AeroSpace Information, 301-621-0390.

13. ABSTRACT (Maximum 200 words)

The effects of cross-sectional area variation on idealized Pulse Detonation Engine performance are examined numerically. A quasi-one-dimensional, reacting, numerical code is used as the kernel of an algorithm that iteratively determines the correct sequencing of inlet air, inlet fuel, detonation initiation, and cycle time to achieve a limit cycle with specified fuel fraction, and volumetric purge fraction. The algorithm is exercised on a tube with a cross sectional area profile containing two degrees of freedom: overall exit-to-inlet area ratio, and the distance along the tube at which continuous transition from inlet to exit area begins. These two parameters are varied over three flight conditions (defined by inlet total temperature, inlet total pressure and ambient static pressure) and the performance is compared to a straight tube. It is shown that compared to straight tubes, increases of 20 to 35 percent in specific impulse and specific thrust are obtained with tubes of relatively modest area change. The iterative algorithm is described, and its limitations are noted and discussed.Optimized results are presented showing performance measurements, wave diagrams, and area profiles. Suggestions for future investigation are also discussed.

14. SUBJECT TERMS 15. NUMBER OF PAGES

Pulse detonation engines; Nozzle design; Nozzle geometry 20

\begin{tabular}{|c|c|c|}
\hline $\begin{array}{c}\text { 17. SECURITY CLASSIFICATION } \\
\text { OF REPORT } \\
\text { Unclassified }\end{array}$ & $\begin{array}{c}\text { 18. SECURITY CLASSIFICATION } \\
\text { OF THIS PAGE } \\
\text { Unclassified }\end{array}$ & $\begin{array}{c}\text { 19. SECURITY CLASSIFICATION } \\
\text { OF ABSTRACT } \\
\text { Unclassified }\end{array}$ \\
\hline
\end{tabular}

